2016-11-02

How to set up and use a Twitter account professionally

Chudleigh, Meriel

http://hdl.handle.net/10026.1/8333

10.7748/ns.2016.e10560

Nursing Standard

RCN Publishing Ltd.

All content in PEARL is protected by copyright law. Author manuscripts are made available in accordance with publisher policies. Please cite only the published version using the details provided on the item record or document. In the absence of an open licence (e.g. Creative Commons), permissions for further reuse of content should be sought from the publisher or author. 
How to series

Communication

\section{How to set up and use a Twitter account professionally}

Chudleigh M, Jones R (2016) How to set up and use a Twitter account professionally. Nursing Standard. Date of submission: 9 May 2016; date of acceptance: 4 August 2016. doi:10.7748/ns.2016.e10560

Meriel Chudleigh

Lecturer in adult nursing, faculty of health and human sciences, School of Nursing and Midwifery, University of Plymouth, Plymouth, England

Ray Jones

Professor of health informatics, faculty of health and human sciences,

School of Nursing and Midwifery, University of Plymouth, Plymouth, England

Correspondence

ray.jones@plymouth.ac.uk

Conflict of interest

None declared

Peer review

This article is subject to external double-blind peer review and checked for plagiarism using automated software

Contributing to the How to series

To suggest a 'How to...' article, please email how.to@rcni.com with a synopsis of your idea

Online

This 'How to' guide is available at: howto.nursingstandard.com. For related articles search the website using the keywords 


\section{Rationale and key points}

This article encourages nurses to use Twitter to engage in professional discussion, share information and raise awareness of alternative views to enhance practice and patient care. Twitter is an online social media service that enables users to send and read 140-character messages called tweets.

- Twitter is free and accessible across multiple platforms and devices, providing immediate contact with professionals, organisations and the public worldwide.

- Many healthcare professionals use Twitter to share ideas and information.

- Responsible use of Twitter creates opportunities to access information, discuss issues and challenge misconceptions to support professional nursing behaviours.

\section{Reflective activity}

'How to' articles can help update your practice and ensure it remains evidence based. Apply this article to your practice. Reflect on and write a short account of:

1. How you could develop your use of Twitter for professional learning and interaction with healthcare professionals and others.

2. How you could support a colleague to use Twitter for professional development.

communication, online discussion, professional development, social media, Twitter

\section{Preparation}

- Download or print and read a copy of the Nursing and Midwifery Council's (NMC) (2015a) guidance on using social media responsibly.

- Read and implement your employer's policies in relation to the use of online technology.

- Before setting up your Twitter account, think about a suitable account name (for example, @something), what will be displayed (for example, Firstname Lastname), and whether you will use a photo or picture. Consider the option of separate accounts for personal and professional use.

- You can have various degrees of anonymity, but disclosing your identity confirms authenticity, and a short biography provides information to encourage people to follow you. It is important to remember that Twitter is a public forum.

\section{Procedure}

1. On a desktop or laptop, access www.twitter.com to set up an account. On a smartphone or tablet, access the app store and download the Twitter app to set up an account. Select 'sign up'.

2. Enter your full name and either your email address or phone number, choose a password and select 'sign up'.

3. Twitter will send you a message with a code that you will need to enter in the relevant box provided.

4. Choose a suitable username, check your personal information and select 'create my account'. Further information about how to set up a Twitter account is available at: https://support.twitter.com/articles/100990 (Twitter 2016a). 
5. Once you have set up a Twitter account, select the magnifying glass symbol to search for people and organisations to follow. Your news feed contains their current tweets. A useful way to find people is to see who others follow. Start with about 30 people for a lively news feed (Table 1).

6. Regularly review who you follow to ensure your news is personalised to your learning needs and interests. Do not expect people you follow to follow you regularly or continuously. Twitter is used for having conversations and people change who they follow as different topics become of interest.

7. Write clear tweets. This is a skill that develops with practice.

8. Look at how others tweet to learn to use Twitter. Look at tweets and respond by clicking on the 'like', 'reply', 'retweet' or 'quote' options (Box 1). Tweets update constantly, so if some are not relevant that does not matter.

9. Initiate or join conversations. Remember to be professional and check your tweets before posting them.

10.Tweetchats are discussions that occur at a prearranged time and cover a specific subject, thus supporting professional networking by providing a forum for focused discussion and information sharing.

11. Use hashtags (\#) to make your tweets easier to find. By searching for a particular hashtag, for example \#WeNurses, you can find other people's tweets - even those you do not follow - who have joined a particular conversation. During tweetchats you can 'lurk' (view the discussion), but you will benefit more by tweeting.

12. Reflect on your learning to support continuing professional development and revalidation. For example tweetchat organisers may provide downloadable participation certificates and you may 'write up' a tweetchat for an essay or 'blog' that might count towards annual appraisal or revalidation.

13. Use Twitter to disseminate information. When browsing the web on mobile devices, select the 'share' symbol. You can also add a comment about a particular website.

14. Although tweets remain available to read for many months, most people only read those posted in the preceding few hours. If you have an important message you can repeat your tweet, perhaps with different wording. Look at time zones, shift patterns and patterns of use of your intended audience. Include pictures or videos to make tweets interesting and engaging.

15. In the context of healthcare, Twitter provides a forum for patients and carers to share their views and opinions. Follow patient organisations to access these views. This will help you enhance person-centred care.

16. Educators can link with others to discuss or debate important issues. Students can connect with other learners to share resources and support.

17. You can use Twitter to promote events to increase engagement both in advance of and during an event, and to access a wider audience, for example by tweeting at conferences.

18. Support others by posting useful information or answering their queries - and they might do likewise. Twitter is a sharing community. Similar to conversations between colleagues over coffee, Twitter provides an opportunity to socialise as well as to share updates and information.

19. Although you can reference Twitter, you should always follow links and search for original articles and sources, and check and use those in refining your practice or in academic work. Tweets might not remain available to those checking references so always consider the validity and accessibility of sources.

20. Twitter is a public forum, therefore your tweets should be carefully considered and professional.

Commented [RJ1]: Tweetchats (one word) is the accepted and widely used term/word.

Commented [RJ2]: As above

Commented [R]3]: Linked to showing link between Twitter and 
Table 1. People and organisations to consider following on Twitter

\begin{tabular}{|l|l|l|}
\hline Nursing & General healthcare & Patient connections \\
\hline @NurseStandard & @FabNHSStuff & @patientopinion \\
\hline @WeNurses & @jrf_uk & @PatientsAssoc \\
\hline @NurChat & $@ N I C E c o m m s$ & @DementiaFriends \\
\hline @nmcnews & @HealthFdn & @UKSepsisTrust \\
\hline @theRCN & @TheKingsFund & @CdiffFoundation \\
\hline @6cslive & @NHSChoices & @ParkinsonsUK \\
\hline @Britainsnurses & $@ N H S L e a d e r s h i p$ & @Patient \\
\hline @advnursing & @HealthCareersUK & @healthtalkorg \\
\hline @Nurse_UK & @NuffieldTrust & @PatientVoicesUK \\
\hline @NurseEdUK & @NHS_HealthEdEng & @DiabetesUK \\
\hline
\end{tabular}

\section{Box 1. Glossary of terms}

- @username A username is how you are identified on Twitter, and is always preceded immediately by the @ symbol.

- Hashtag A hashtag is any word or phrase immediately preceded by the \# symbol. When you select a hashtag, you will see other tweets containing the same keyword or topic.

- Like Liking a tweet indicates that you appreciate it. You can find all of your likes by selecting the 'likes' tab on your profile.

- Notifications The notifications timeline displays your interactions with other Twitter users, such as mentions, favourites, retweets and who has followed you recently.

- Profile Your profile displays information you choose to share publicly, as well as all of the tweets you have posted. Your profile along with your @username identify you on Twitter.

- Reply A reply is a response to another person's tweet by clicking on the reply button.

- Retweet A retweet is when you share another person's tweet by clicking on the retweet button.

(Twitter 2016b) 


\section{Evidence base}

The healthcare environment is rapidly changing and nurses need to remain abreast of any advances in technology and practice, and ensure their skills and knowledge are up to date to maintain competence (NMC 2015b). Time pressures and autonomous working might mean nurses have limited opportunities to discuss practice, issues and challenges with colleagues. Isolated workplaces and shift work may limit access to wider healthcare communities, potentially resulting in local practice that is unquestioning.

Nurses can use Twitter to:

- Keep their knowledge and skills up to date, and develop and improve their practice.

- Remain abreast of changes in healthcare because this area is challenging and constantly changing.

- Engage in in-depth learning.

- Enhance professional development through networking and responsible use of social media.

The NHS is experiencing significant service demand and financial pressures (NHS England 2015). With advances and growth in the use of social media, nurses require training to develop their information technology skills as well as encouragement to use social media to expedite change (The Health Foundation 2015). Although Archibald and Clark (2014) claimed that nurses are slow in their uptake of Twitter, there are many nurses using this platform in communities such as@WeNurses and @Nurchat, and some universities include Twitter as an assessed element of the undergraduate nursing curriculum (Jones et al 2016).

Nurses can use social media platforms such as Twitter to connect with other healthcare professionals, patient groups and the wider healthcare community. They benefit from contact with professional 'communities of practice', which are groups of people who share an interest and/or a profession and engage in collective learning through sharing information and experience. Specialist knowledge and skills develop through increasing contact and discourse with communities of practice (Lave and Wenger 1991).

Twitter dialogue can involve healthcare professionals, students, service users and representatives of influential national and international organisations. Therefore, discussion can be wide-ranging.

Cognitive psychological theory of socially constructed knowledge suggests that novices use the language and their interpretation of professional identities as expressed by others in their learning networks to develope their own language and identity (Webb et al 2009). Unquestioningly adopting local practice might occur as a result of limited exposure to innovation, wider practice and professional analysis. Access to an extensive, knowledgeable community of practice through Twitter can bridge this learning gap.

Composing a tweet involves refining one's thoughts and being succinct (Cottrell and Morris 2012). Twitter is a dynamic conversational process, involving selecting, adding and redistributing knowledge (Gillen and Merchant 2012). Twitter focuses on public discussion rather than personal details about the individual (Hughes et al 2012). This might be one of the reasons why many nursing communities of practice use this forum to support professional practice.

Careless use of social media can pose a risk. The Code (NMC 2015b) requires that nurses uphold the reputation of their profession at all times, which includes using social media and networking sites responsibly, and respecting others' privacy. The NMC (2015a) provides additional guidance on using social media responsibly and notes 'the scope of social media is constantly evolving' and needs responsive regulation. However, Beard (2013) claimed draconian policies prohibiting social media use are ineffective because of a wide and active user group.

A post on Twitter is automatically visible to the public, but it could be argued that everything posted anywhere online, even in apparently closed groups, has the potential to be made public. Professional

Commented [RJ5]: Reference added

Commented [RJ6]: Sentence edited - is that clearer?

Commented [RJ7]: This is author assertion on the basis that the NMC argue (correctly) that social media is constantly evolving.

Commented [RJ8]: Edited - is that clearer now? 
behaviour remains the responsibility of the individual; consideration for others and appropriate choice are taught in undergraduate nurse education (Jones et al 2016) and should be demonstrated and exercised throughout one's career.

Nurses must have up-to-date knowledge through technological literacy and connections to influence decisions and action change. Twitter contacts can allow the development of these skills.

Disclaimer

Please note that information provided by Nursing Standard is not sufficient to make the reader competent to perform the task. All clinical skills should be formally assessed at the bedside by a nurse educator or mentor. It is the nurse's responsibility to ensure their practice remains up to date and reflects the latest evidence

\section{Useful resources}

Nurchat: www.newcrosshealthcare.com/nurchat-home

Royal College of Nursing (2015) Getting Started on Twitter www.rcn.org.uk/professionaldevelopment/publications/pub-005031

Wecommunities http://wecommunities.org/resources/twitterversity

\section{References}

Archibald MM, Clark AM (2014) Twitter and nursing research: how diffusion of innovation theory can help uptake. Journal of Advanced Nursing. 70 :

Beard E (2013) Nurse leaders and the use of social media: becoming literate to lead. Nurse Leader. 11, 6, 38-40.

Cottrell S, Morris N (2012) Study Skills Connected: Using Technology to Support Your Studies. Palgrave Macmillan, London.

Gillen J, Merchant G (2012) Contact calls: Twitter as a dialogic social and linguistic practice. Language Sciences. 35, 47-58.

Hughes DJ, Rowe M, Batey M et al (2012) A tale of two sites: Twitter vs. Facebook and the personality predictors of social media usage. Computers in Human Behavior. 28, 2, 561-569.

Jones R, Kelsey J, Nelmes $P$ et al (2016) Introducing Twitter as an assessed component of the undergraduate nursing curriculum. Journal of Advanced Nursing. 72, 7, 1638-1653.

Lave J, Wenger E (1991) Situated Learning: Legitimate Peripheral Participation. Cambridge University Press, Cambridge.

NHS England (2015) The NHS Five Year Forward View. https://www.england.nhs.uk/wp-content/uploads/2014/10/5yfv-web.pdf (Last accessed: 22 September 2016.)

Nursing and Midwifery Council (2015a) Guidance on Using Social Media Responsibly. www.nmc.org.uk/globalassets/sitedocuments/nmcpublications/social-media-guidance.pdf (Last accessed: 22 September 2016)

Nursing and Midwifery Council (2015b) The Code: Professional Standards of Practice and Behaviour for Nurses and Midwives. www.nmc.org.uk/globalassets/sitedocuments/nmc-publications/nmc-code.pdf (Last accessed: 22 September 2016.)

The Health Foundation (2015) Shaping the Future: A Strategic Framework for a Successful NHS. www.health.org.uk/sites/health/files/ShapingTheFuture.pdf (Last accessed: 22 September 2016.)

Twitter (2016a) Signing up with Twitter. https://support.twitter.com/articles/100990 (Last accessed: 22 September 2016.)

Twitter (2016b) The Twitter Glossary. https://support.twitter.com/articles/166337 (Last accessed: 22 September 2016. )

Webb G, Fawns R, Harre R (2009) Professional identities and communities of practice. In Delany C, Molloy E (Ed) Clinical Education in the Health Professions. Churchill Livingstone Elsevier, Chatswood, 53-69.
Commented [RJ9]: Edited as requested

Commented [RJ10]: Changed as requested 